\title{
Fabrication of Conductive Polypyrrole Nanofibers by Electrospinning
}

\author{
Yiqun Cong, Shize Liu, and Haifeng Chen \\ Department of Biomedical Engineering, College of Engineering, Peking University, Beijing 100871, China \\ Correspondence should be addressed to Haifeng Chen; haifeng.chen@pku.edu.cn
}

Received 5 July 2013; Accepted 3 September 2013

Academic Editor: Krasimir Vasilev

Copyright (C) 2013 Yiqun Cong et al. This is an open access article distributed under the Creative Commons Attribution License, which permits unrestricted use, distribution, and reproduction in any medium, provided the original work is properly cited.

\begin{abstract}
Electrospinning is employed to prepare conductive polypyrrole nanofibers with uniform morphology and good mechanical strength. Soluble PPy was synthesized with NaDEHS as dopant and then applied to electrospinning with or without PEO as carrier. The PEO contents had great influence on the morphology and conductivity of the electrospun material. The results of these experiments will allow us to have a better understanding of PPy electrospun nanofibers and will permit the design of effective electrodes in the BMIs fields.
\end{abstract}

\section{Introduction}

Electrospinning is a broadly applied technology used to fabricate nanofibers from a wide range of materials including both natural and synthetic polymers [1]. A high voltage electrostatic field is used to induce the ejection of a liquid jet which stretches into continuous fibers in the submicron range [2]. The electrospun material exhibits unique features such as uniform ultrafine fibers, high surface-to-volume ratio, tunable porous structures, and controllable composition, making it capable to achieve the desired result from its prosperities and functionality. These qualities allow the materials to be successfully applied in various fields such as biosensor [3], tissue engineering scaffold [4], drug delivery [5], wound dressing [6], and protective clothing [7].

Polypyrrole (PPy) is one of the most widely investigated conductive polymers due to its easy synthesis, high conductivity, good environmental stability, and biocompatibility [2]. In the past decades, it has been applied in biosensors [8], electrodes [9], and especially nerve tissue engineering scaffolds [10]. For instance, George et al. [11] found that the PPy film could support the growth of nerve system. Either of these applications would prefer to have a high surface area for a given mass or volume, which would provide a large interface in sensing, to enhance the ions transportation for electrode or to promote cell growth as the scaffold. This could be realized using electrospinning to generate PPy nanofibers with porous structure. It is possible to coat the electrospun PPy nanofibers on materials like electrodes prior to inserting them in the brain which can help relieve some damage done to the tissues as well as provide better results due to the more positive interaction between the coated electrodes and the cells. This will be helpful to the development of brainmachine interfaces (BMIs) biomedical devices.

In the present work, we have developed a way to electrospinning PPy solution with carrier into ultrafine fibers. Using scanning electron microscopy (SEM), Fourier transforminfrared spectroscopy (FTIR), XPS, and four-probe method, the morphology, chemical composition, and conductivity of the nanofibers were examined. The results of these experiments will allow us to have a better understanding of PPy electrospun nanofibers and will permit the design of effective electrodes in the BMIs fields.

\section{Experimental}

2.1. Synthesis of Soluble PPy [12]. Soluble PPy was synthesized at $0^{\circ} \mathrm{C}$ by $0.06 \mathrm{~mol} \mathrm{NaDEHS}$ (Sigma-Aldrich) dissolved in $180 \mathrm{~mL}$ distilled water as the dopant and $0.12 \mathrm{~mol}$ Pyrrole (Sinopharm) added. 0.018 mol APS (Xilong Chemical) dissolved in $20 \mathrm{~mL}$ distilled water solely as the oxidant was slowly added into the NaDEHS solution with vigorous string. The polymerization was carried out for $24 \mathrm{~h}$ at $0^{\circ} \mathrm{C}$ and 


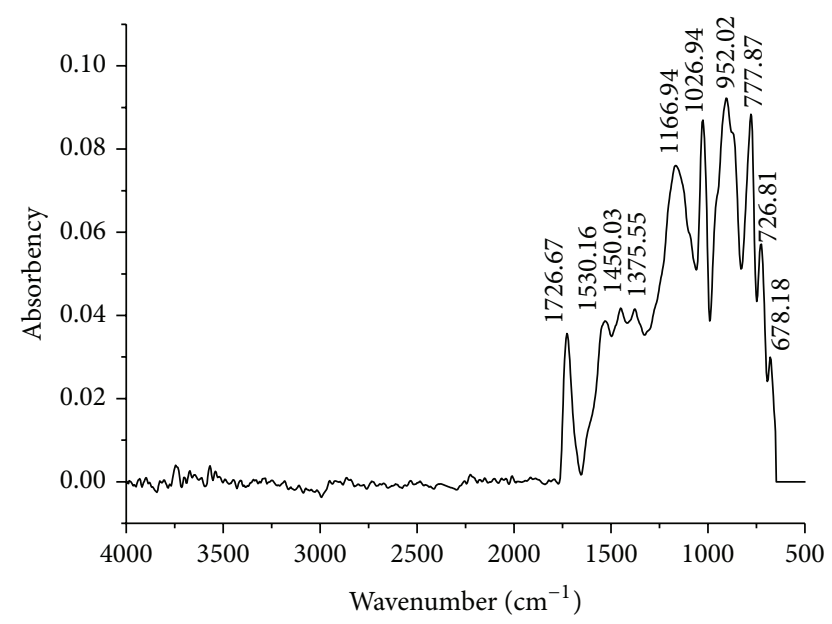

Figure 1: FT-IR Spectrum of NaDEHS doped PPy.

terminated by pouring the solution into methanol. The PPy powder was collected by filtering and was dried at $60^{\circ} \mathrm{C}$ for $24 \mathrm{~h}$.

FT-IR (Magna-IR 750, Nicole) and XPS (Axis Ultra, Kratos) were employed to demonstrate the PPy powder.

2.2. Electrospinning of PPy Fibers. PPy and PEO were dissolved in $\mathrm{CHCl}_{3}$ with the concentration $8 \mathrm{wt} \%$ and $4 \mathrm{wt} \%$, respectively. $\mathrm{PEO}$ and $\mathrm{PPy}$ solutions were then mixed with the ratios of $1: 10,1: 8,1: 6,1: 4$, and $1: 2$. The $8 \mathrm{wt} \% \mathrm{PPy}$ and $\mathrm{PEO} / \mathrm{PPy}$ blends were prepared for electrospinning.

Electrospinning was carried out with a $10 \mathrm{kV}$ voltage and $0.8 \mathrm{~mL} / \mathrm{h}$ flow rate. A ground screen covered by aluminum sheet was placed $10 \mathrm{~cm}$ from the tip of the syringe. The nonwoven fibers were collected and characterized by SEM (Quanta 200F, FEI).

2.3. Conductivity Characterization. The conductivity of each sample is measured using the four-probe method. Afterwards, the $1: 10$ ratio $\mathrm{PEO} / \mathrm{PPy}$ nanofibers was kept in the $30^{\circ} \mathrm{C}, 40^{\circ} \mathrm{C}, 50^{\circ} \mathrm{C}, 60^{\circ} \mathrm{C}$, and $70^{\circ} \mathrm{C}$ atmosphere orderly, and the conductivity at each temperature was recorded.

\section{Results}

3.1. Synthesis of Soluble PPy. The formation of PPy and the doping of NaDEHS are confirmed with FT-IR spectroscopy in the range of $4000-650 \mathrm{~cm}^{-1}$ as shown in Figure 1. The peak at 905.0 is associated to the out-of-plane vibration of $=\mathrm{C}$ $\mathrm{H}$; the wide peak at $1166.9 \mathrm{~cm}^{-1}$ is associated with the $\mathrm{N}-\mathrm{C}$ stretching; and the peaks at $1373.55 \mathrm{~cm}^{-1}$ and $1026.94 \mathrm{~cm}^{-1}$ are corresponding to the $=\mathrm{C}-\mathrm{H}$ plan vibration, while the peak at $1726.67 \mathrm{~cm}^{-1}$ corresponds to the $\mathrm{C}=\mathrm{O}$ vibration in NaDEHS.

The XPS analysis is shown in Figure 2 while the quantitative element analysis is in Table 1 . The $\mathrm{N}$ element is from PPy, while the presence of $\mathrm{S}$ and $\mathrm{Na}$ confirmed the doping of NaDEHS.

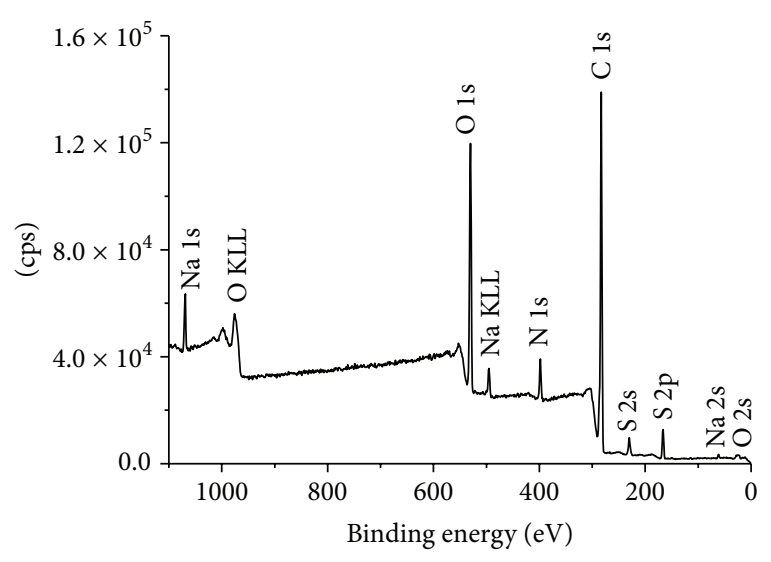

FIGURE 2: XPS analysis of NaDEHS doped PPy.

TABLE 1: Quantitative element analysis of NaDEHS doped PPy.

\begin{tabular}{lccc}
\hline Name & Position & Area & \% Conc. \\
\hline Na 1s & 1071.65 & 2592.8 & 0.28 \\
S 2p & 168.00 & 6989.5 & 1.89 \\
N 1s & 399.95 & 16082.2 & 6.10 \\
O 1s & 531.80 & 67833.9 & 15.73 \\
C 1s & 284.80 & 116790.6 & 76.00 \\
\hline
\end{tabular}

3.2. Morphology of PPy Nanofibers. Figure 3 presents the SEM images of electrospun PEO/PPy nanofibers with different ratios. PPy nanofibers are nonuniform with droplets, and the material is fragile. When PEO is added, cylindrical fibers are formed. As the ratio of PEO increases, there are less droplets and broken ends. The diameter statistics of fibers of PEO/PPy nanofibers are shown in Figure 4. The fibers are thinner, and the diameters are more uniform with more PEO component due to the change of solution viscosity and surface tension.

3.3. Conductivity. There is a linear relationship between the conductivity of these nanofibers and the content of PEO as shown in Figure $5\left(R^{2}=0.9571\right)$. As the content of PEO varies, the conductivity increased by one-order of magnitude ranged from $1.44 \times 10^{-3} \mathrm{~S} \cdot \mathrm{cm}^{-1}$ to $2.45 \times 10^{-4} \mathrm{~S} \cdot \mathrm{cm}^{-1}$.

By increasing the temperature, we found that the conductivity of the $1: 10$ ratio $\mathrm{PEO} / \mathrm{PPy}$ nanofibers rises following the power function $\sigma=A \exp (\mathrm{B} / \mathrm{T})\left(R^{2}=0.9939\right)$, which is a typical property of semiconductor.

\section{Discussion}

These significant characteristic peaks of PPy in the FT-IR spectrum demonstrate the formation of $\mathrm{PPy}$, while the $\mathrm{C}=\mathrm{O}$ liberation peak at $1726.67 \mathrm{~cm}^{-1}$ in FT-IR spectrum and the $\mathrm{S}$ and $\mathrm{Na}$ elements in XPS characterization illustrate that the NaDEHS has been successfully doped into PPy. In the quantitative element analysis, the ratio of $\mathrm{N}$ and $\mathrm{S}$ is about $3.2: 1$, suggesting that in the polymer chain the mole ratio of Py unit and NaDEHS is around 3. As the pure PPy 


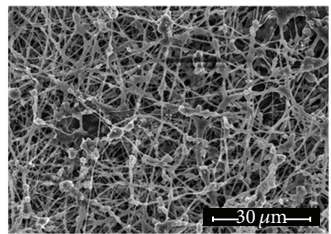

(a1)

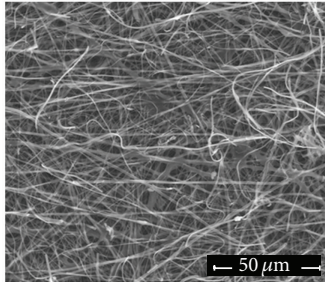

(a2)

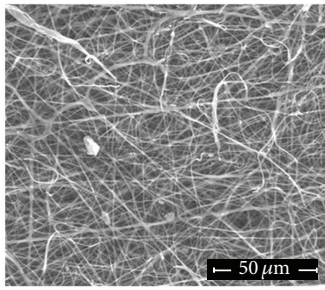

(a3)

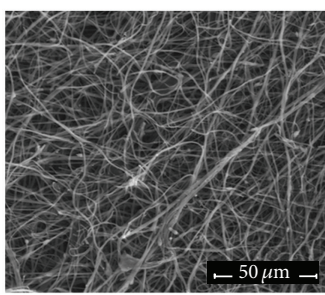

(a4)

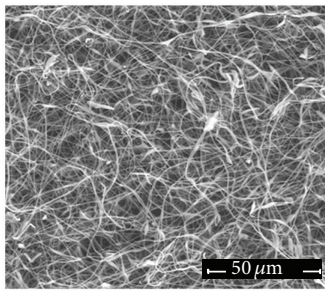

(a5)

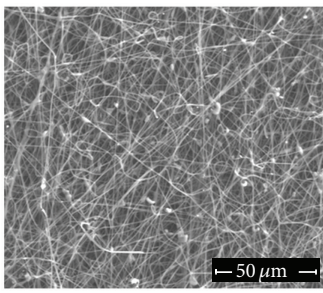

(a6)

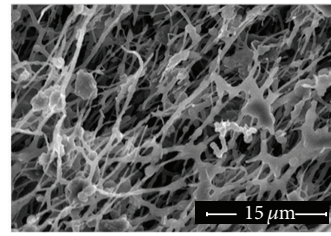

(b1)

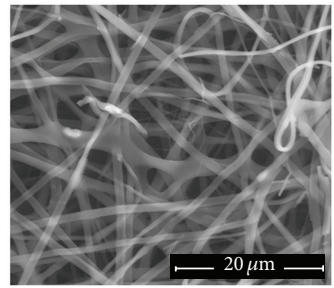

(b2)

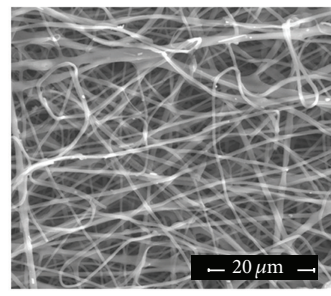

(b3)

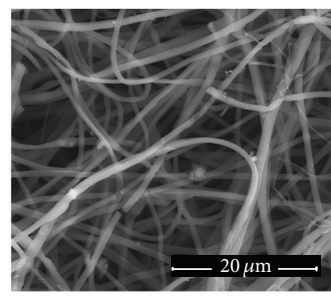

(b4)

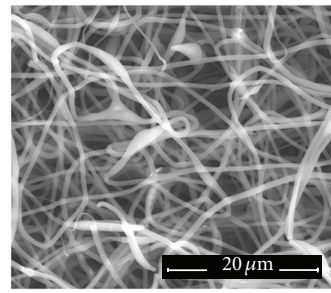

(b5)

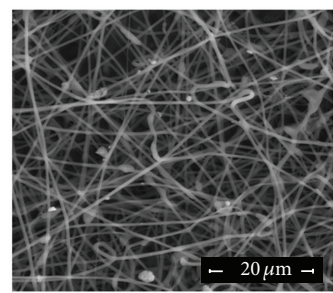

(b6)

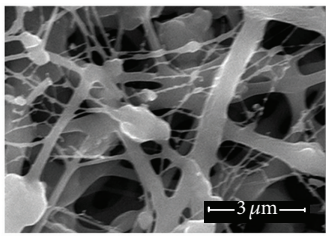

(c1)

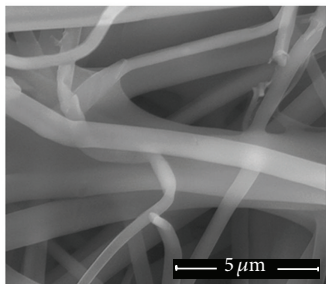

(c2)

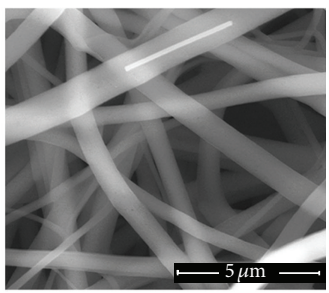

(c3)

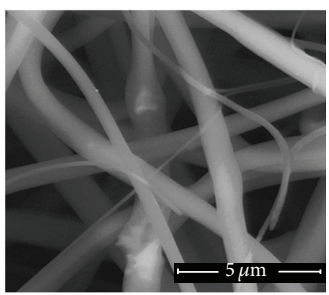

(c4)

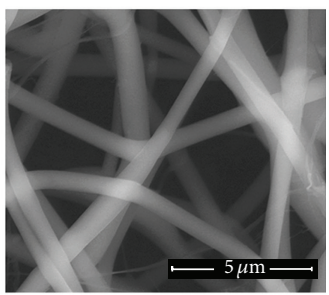

(c5)

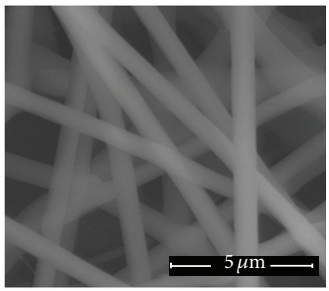

(c6)

FIGURE 3: SEM micrographs of PEO/PPy electrospun fibers. (a1),(b1),(c1) PPy nanofibers without PEO; (a2),(b2),(c2) 1:10 PEO/PPy fibers; (a3),(b3),(c3) 1:8 PEO/PPy fibers; (a4),(b4),(c4) 1:6 PEO/PPy fibers; (a5),(b5),(c5) 1:4 PEO/PPy fibers; (a6),(b6),(c6) 1:2 PEO/PPy fibers. 


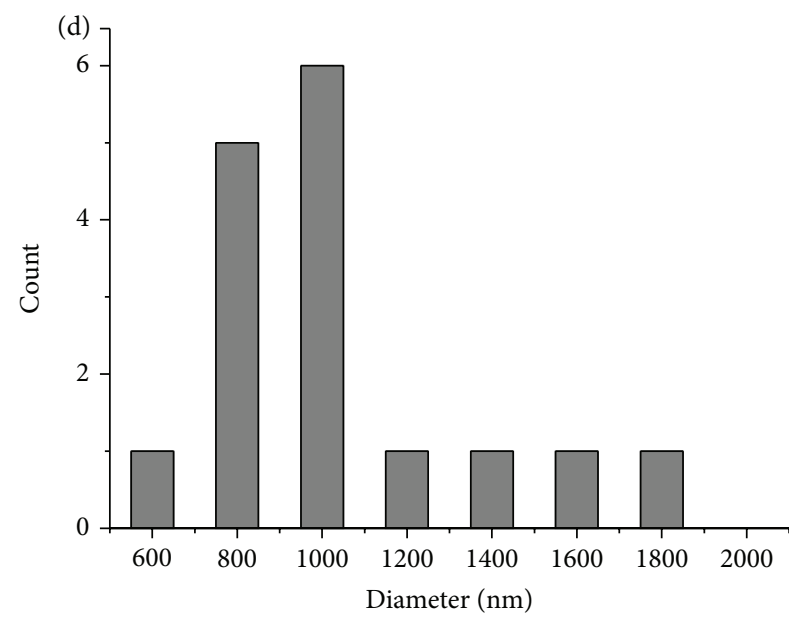

(a)

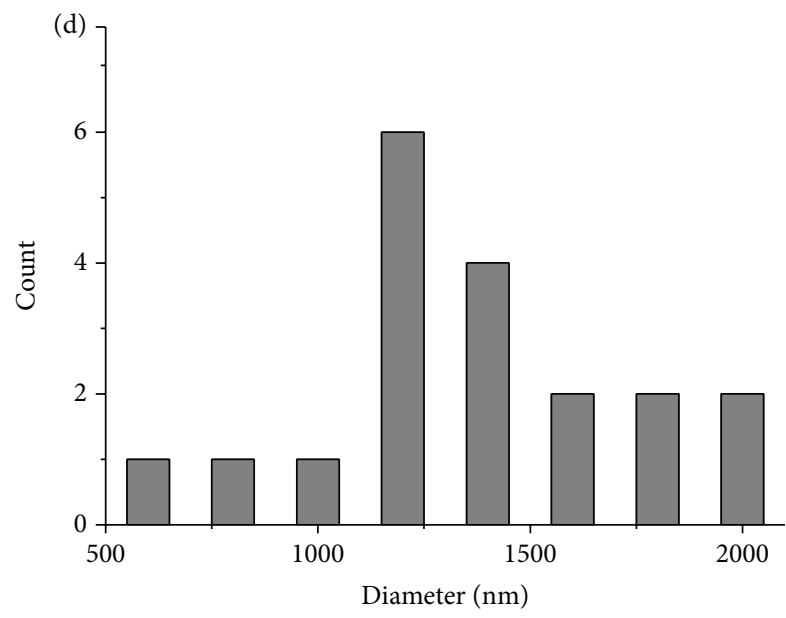

(c)

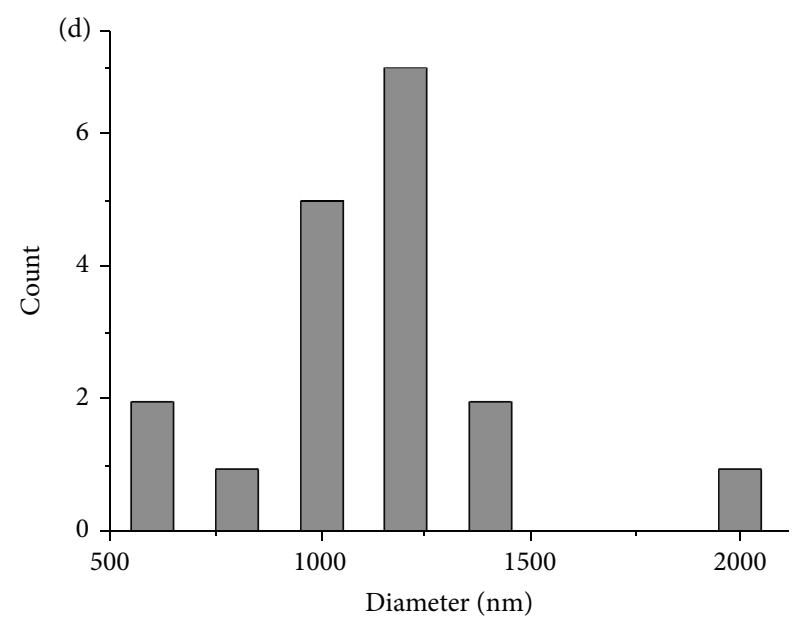

(b)

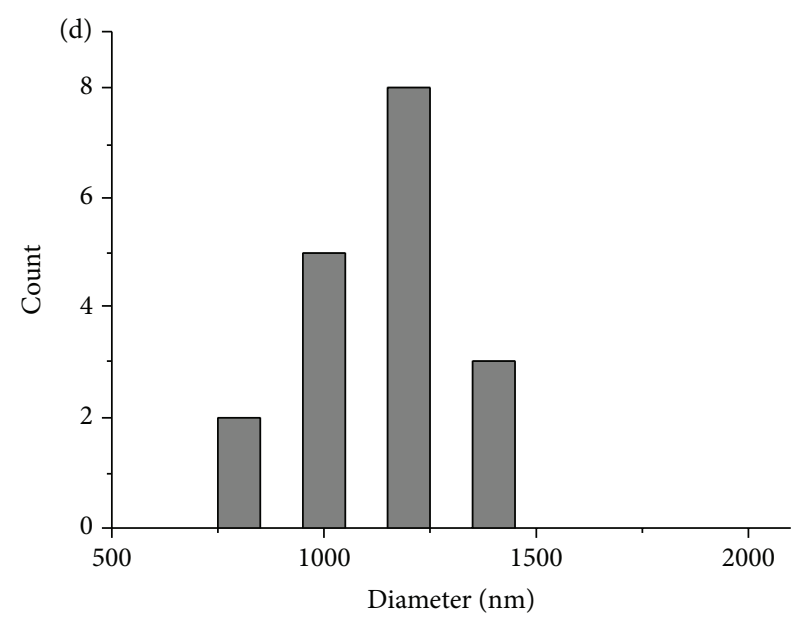

(d)

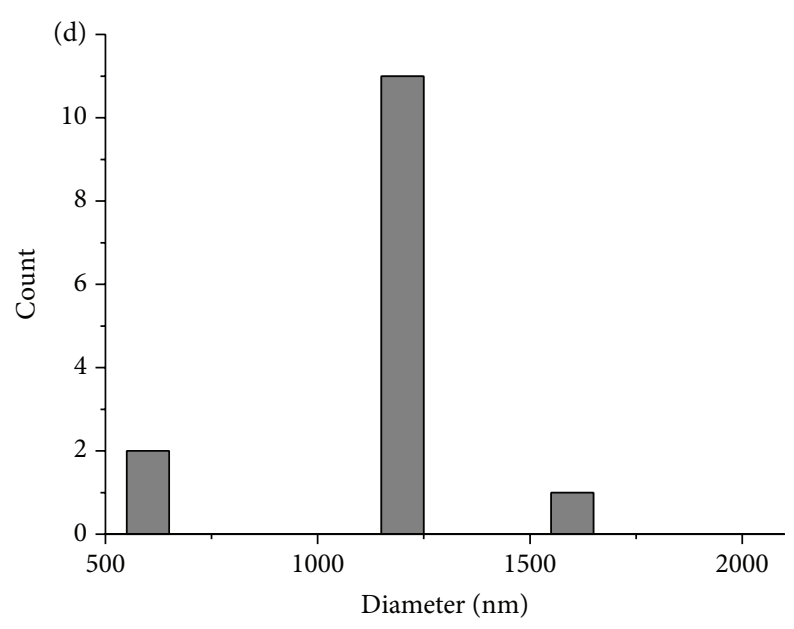

(e)

FIGure 4: Statistics of PEO/PPy fiber diameter. (a) 1:10 PEO/PPy fibers; (b) 1:8 PEO/PPy fibers; (c) 1:6 PEO/PPy fibers; (d) 1:4 PEO/PPy fibers; (e) 1:2 PEO/PPy fibers.

powder is insoluble in most solvent due to the strong internal interactions within and between the chains; the doping of $\mathrm{NaDEHS}$ result in the solubility in $\mathrm{CHCl}_{3}$.

The doped PPy solution cannot be preceded into smooth fibers, and the electrospun web is fragile. To enhance the electrospinning process, PEO is added as carrier, and the resulted fibers are much more smooth and ultrafine.

The droplets and broken ends in the fibers are because of inadequate viscosity, which could be increased by adding $\mathrm{PEO}$ into PPy solution. So the fibers become longer and more 


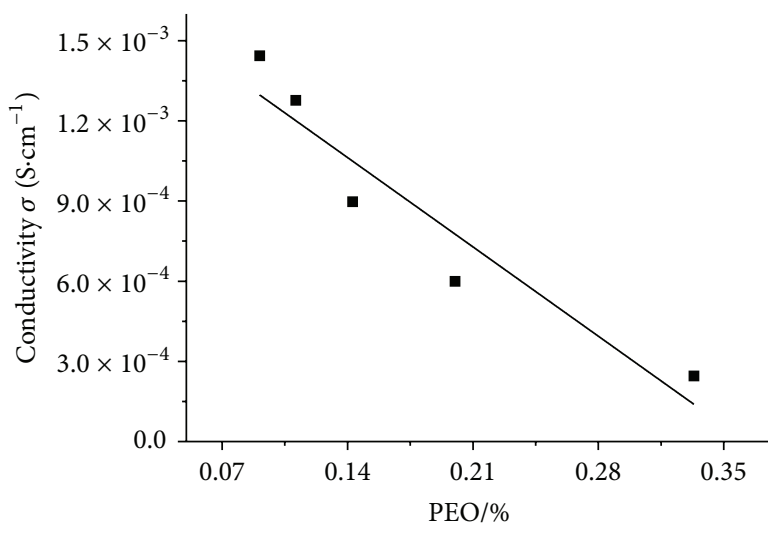

(a)

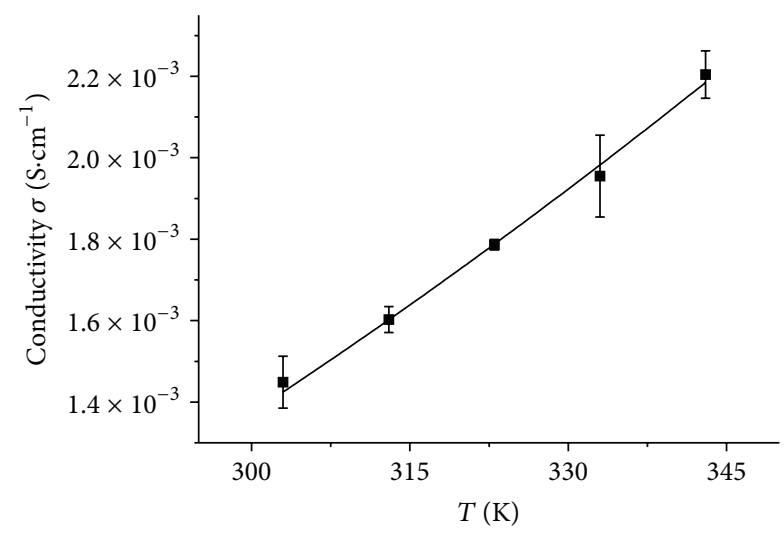

(b)

FIgUre 5: Electrical conductivity of PEO/PPy nanofibers as a function of PEO content and 1:10 PEO/PPy nanofibers as function of temperature. (a) Electrical conductivity of $\mathrm{PEO} / \mathrm{PPy}$ nanofibers as a function of $\mathrm{PEO}$ content; (b) electrical conductivity of $1: 10 \mathrm{PEO} / \mathrm{PPy}$ nanofibers as function of temperature.

uniform as the ratio of PEO and PPy rise. As in the $1: 2$ $\mathrm{PEO} / \mathrm{PPy}$ electrospun materials, the long nanofibers exhibit a cylindrical morphology and are randomly distributed in a uniform and dense way. Since PEO is a flexible material, the mechanical strength of $\mathrm{PEO} / \mathrm{PPy}$ nanofibers is improved.

The size of the fibers could also be affected by the ratio of $\mathrm{PEO}$ and PPy. As the viscosity increases, the surface tension, which the dividing of the jets has to overcome, also increases. So the splitting ability of the jets declines and results in thicker fibers. Without the splitting, the diameters of the fibers exhibit narrower distribution.

Although the electrospinning process is promoted, the conductivity of the material will reduce and exhibit a liner relation with the contents of PEO. Pure PPy is semiconductor because of the delocalized $\pi$ bond, while the presence of PEO molecular leads to the fold and twist of the conjugated chain, which would limit the delocalization of electrons. Also, the conductive PPy content will become discontinuous because of PEO, which finally reduce the conductivity.

For semiconductor, as the temperature rises, more electrons are activated and transit into conduction band. Meanwhile, the migration rate will also grow with the temperature, resulting in the better conductivity of the material. In the study of the 1:10 PEO/PPy electrospun material, the conductivity grows with temperature following the power function, demonstrating that after adding PEO, the PPy remains to be semiconductor.

\section{Conclusion}

In summary, the soluble PPy is synthesized by doping NaDEHS. The conductive nanofibers web could be fabricated by electrospun $\mathrm{PEO} / \mathrm{PPy}$ composite. Increase in the content of PEO will enhance the electrospinning process and the mechanical strength of the fiber web but meanwhile reduce the conductivity. Also, the conductivity will increase as temperature rises following a power function like most semiconductors. This work shows the potential of applying electrospun PPy nanofibers to the BMIs fields.

\section{Acknowledgment}

The work is supported by the Ministry of Science and Technology of China (Grants 2012CB933903).

\section{References}

[1] N. Bhardwaj and S. C. Kundu, "Electrospinning: a fascinating fiber fabrication technique," Biotechnology Advances, vol. 28, no. 3, pp. 325-347, 2010.

[2] T. S. Kang, S. W. Lee, J. Joo, and J. Y. Lee, "Electrically conducting polypyrrole fibers spun by electrospinning," Synthetic Metals, vol. 153, no. 1-3, pp. 61-64, 2005.

[3] Y. Liu, H. Teng, H. Hou, and T. You, "Nonenzymatic glucose sensor based on renewable electrospun Ni nanoparticle-loaded carbon nanofiber paste electrode," Biosensors and Bioelectronics, vol. 24, no. 11, pp. 3329-3334, 2009.

[4] S. Agarwal, J. H. Wendorff, and A. Greiner, "Use of electrospinning technique for biomedical applications," Polymer, vol. 49, no. 26, pp. 5603-5621, 2008.

[5] Z. M. Huang, C. L. He, A. Z. Yang et al., "Encapsulating drugs in biodegradable ultrafine fibers through co-axial electrospinning," Journal of Biomedical Materials Research Part A, vol. 77, no. 1, pp. 169-179, 2006.

[6] J. Jia, Y. Y. Duan, S. H. Wang, S. F. Zhang, and Z. Y. Wang, "Preparation and characterization of antibacterial silvercontaining nanofibers for wound dressing applications," Journal of US-China Medical Science, vol. 4, pp. 52-54, 2007.

[7] S. Ramakrishna, K. Fujihara, W. E. Teo, T. Yong, Z. Ma, and R. Ramaseshan, "Electrospun nanofibers: solving global issues," Materials Today, vol. 9, no. 3, pp. 40-50, 2006.

[8] N. K. Guimard, N. Gomez, and C. E. Schmidt, "Conducting polymers in biomedical engineering," Progress in Polymer Science, vol. 32, no. 8-9, pp. 876-921, 2007. 
[9] B. Veeraraghavan, J. Paul, B. Haran, and B. Popov, "Study of polypyrrole graphite composite as anode material for secondary lithium-ion batteries," Journal of Power Sources, vol. 109, no. 2, pp. 377-387, 2002.

[10] J. Y. Lee, C. A. Bashur, A. S. Goldstein, and C. E. Schmidt, "Polypyrrole-coated electrospun PLGA nanofibers for neural tissue applications," Biomaterials, vol. 30, no. 26, pp. 4325-4335, 2009.

[11] P. M. George, A. W. Lyckman, D. A. Lavan et al., "Fabrication and biocompatibility of polypyrrole implants suitable for neural prosthetics," Biomaterials, vol. 26, no. 17, pp. 3511-3519, 2005.

[12] K. S. Jang, S. S. Han, J. S. Suh, and E. J. Oh, "Synthesis and characterization of alcohol soluble polypyrrole," Synthetic Metals, vol. 119, no. 1-3, pp. 107-108, 2001. 

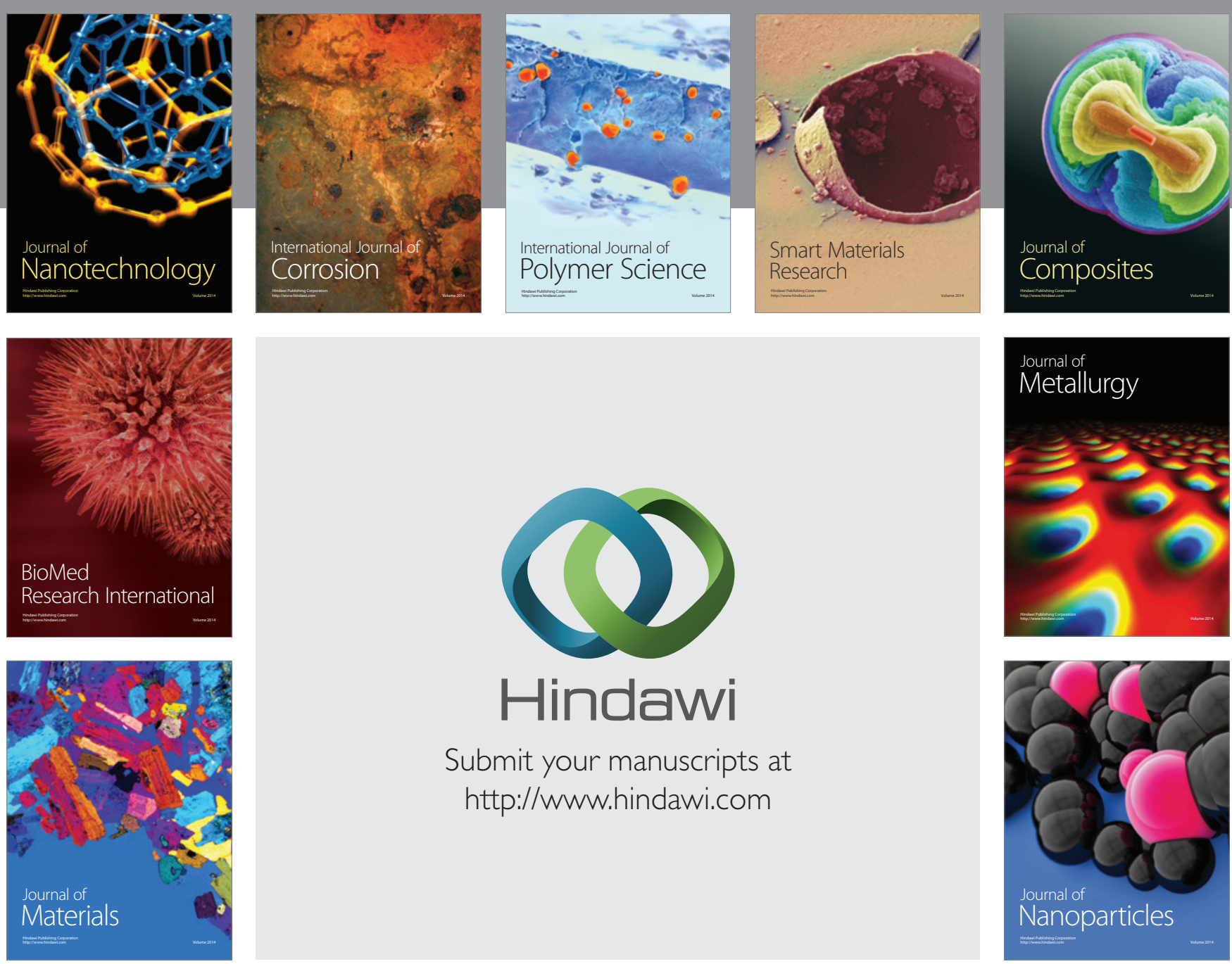

Submit your manuscripts at http://www.hindawi.com
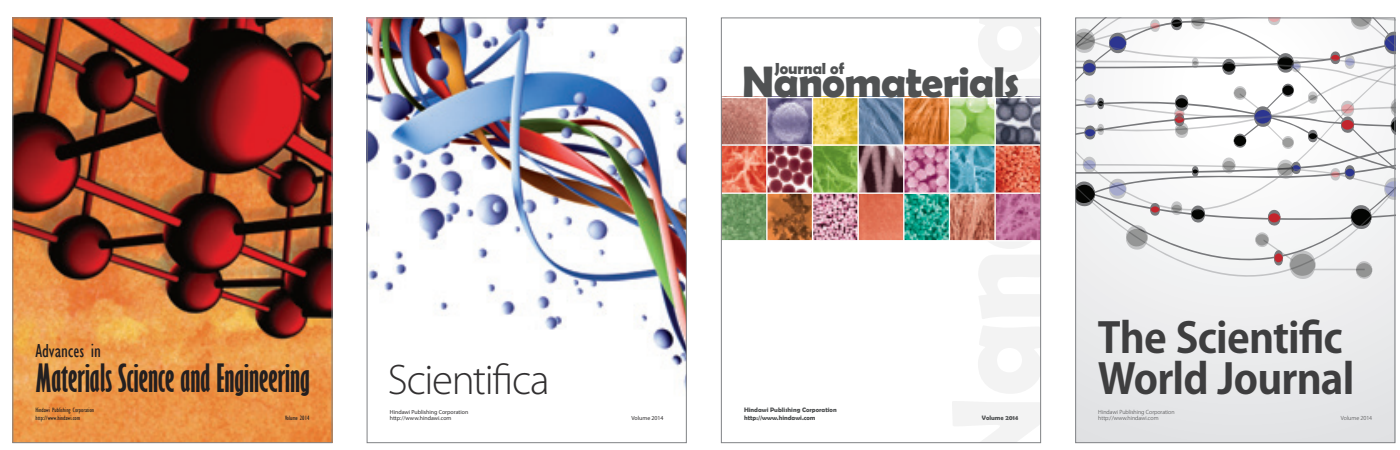

\section{The Scientific World Journal}
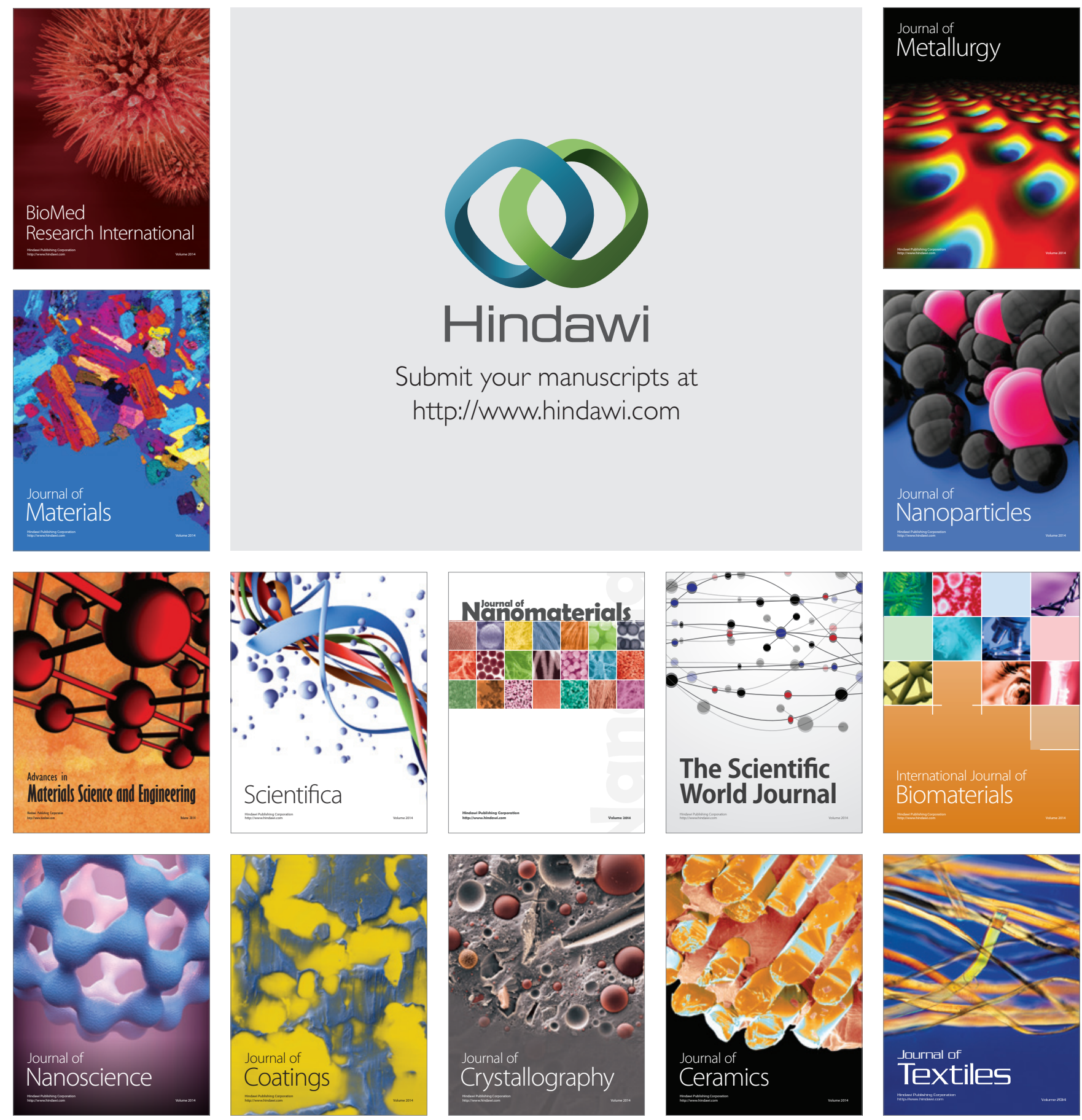